\title{
Gaoligongidris planodorsa, a New Genus and Species of the Ant Subfamily Myrmicinae from China with a Key to the Genera of Stenammini of the World (Hymenoptera: Formicidae)
}

\author{
by \\ Zheng-Hui $\mathrm{Xu}^{1}$

\section{ABSTRACT}

A new genus and species of the ant subfamily Myrmicinae collected from the Gaoligong Mountain Nature Reserve of the Hengduan Mountains, southwestern China, is described. The new genus, Gaoligongidris gen. nov., is close to Lasiomyrma Terayama \& Yamane, but with anterior clypeal margin not angled, metanotal groove deeply impressed, propodeal spiracles large, propodeal spines long and slender, and petiolar peduncle longer than the node. The new genus is distributed in the Oriental region and belongs to the tribe Stenammini of Myrmicinae. A key to the known genera of Stenammini of the world based on worker and queen castes is provided.

Key words: Hymenoptera, Formicidae, Myrmicinae, Gaoligongidris, New genus, China.

\section{INTRODUCTION}

After the publication of the Identification Guide to the Ant Genera of the World (Bolton 1994), 14 new living genera of Myrmicinae have been established in the world. Of these, 12 genera have been recognized as valid ones, and 3 genera (Lasiomyrma Terayama \& Yamane, 2000; Austromorium Shattuck, 2009; Propodilobus Branstetter, 2009) belong to the tribe Stenammini (Bolton 2011).

A new genus, Gaoligongidris gen. nov., was discovered in the ant diversity investigation of Gaoligong Mountain Nature Reserve, southwestern China. The type species, $G$. planodorsa sp. nov., is the only known species of the genus. The new genus is distributed in the Oriental region and belongs to the tribe Stenammini of Myrmicinae. Currently, 20 genera of Stenammini

\footnotetext{
${ }^{1}$ Key Laboratory of Forest Disaster Warning and Control in Yunnan Province, College of Forestry, Southwest Forestry University, Kunming, Yunnan Province 650224, China, E-mail: xuzhenghui1962@163.com
} 
are recognized in the world (Bolton 1995, 2011). In order to understand the differentiation between the new genus and other ones, a key to the known genera of Stenammini is provided.

\section{MATERIALS AND METHODS}

The worker caste of the type species, G. planodorsa sp. nov., was collected by the sample-plot method. Descriptions and measurements were made under a XTB-1 stereo microscope with a micrometer. Illustrations were made under a Motic-700Z stereo microscope with illustrative equipment.

Standard measurements and indices are as defined in Bolton (1987), in addition, ED is supplemented:

TL-Total Length: The total outstretched length of the ant from the mandibular apex to the gastral apex.

HL-Head Length: The length of the head proper, excluding the mandibles, measured in a straight line from the mid-point of the anterior clypeal margin to the mid-point of the occipital margin, in full-face view. In species where the occipital margin or the clypeal margin is concave, the measurement is taken from the mid-point of a transverse line spanning the anteriormost or posteriormost projecting points, respectively.

HW-Head Width: The maximum width of the head in full face view, excluding the eyes.

CI-Cephalic Index $=\mathrm{HW} \times 100 / \mathrm{HL}$.

SL-Scape Length: The maximum straight line length of the antennal scape excluding the basal constriction or neck close to the condylar bulb.

SI-Scape Index $=$ SL $\times 100 / \mathrm{HW}$.

ED-Eye Diameter: The maximum diameter of the eye.

PW-Pronotal Width: The maximum width of the pronotum in dorsal view.

AL-Alitrunk Length: The diagonal length of the alitrunk in profile view from the point at which the pronotum meets the cervical shield to the posterior base of the metapleuron.

All measurements are expressed in millimeters.

The type specimens are deposited in the Insect Collection, Southwest Forestry University (SWFU), Kunming, Yunnan Province, China. 


\section{KEY TO KNOWN GENERA OF STENAMMINI OF THE WORLD BASED ON WORKER AND QUEEN CASTES}

1 Antennae 9-segmented (Malaysia)........ Rostromyrmex Rosciszewski, 1994

- Antennae 11- or 12-segmented ...................................................................... 2

2 Antennae 11-segmented....................................................................................

- Antennae 12-segmented ............................................................................. 10

3 Antennal scrobes present .................................................................................

- Antennal scrobes absent.................................................................................

4 Ventral surfaces of petiole and postpetiole with spongiform appendages (Indo-Australian) ................................ Dacetinops Brown \& Wilson, 1957

- Ventral surfaces of petiole and postpetiole without spongiform appendages.....

5 Anterior margin of clypeus with a pair of fork-like teeth in the middle (Afrotropical) Dicroaspis Emery, 1908

- Anterior margin of clypeus without a pair of fork-like teeth in the middle

6 Counting from the apex, the third antennal segment long, about as long as the second one (Afrotropical................................. Cyphoidris Weber, 1952

- Counting from the apex, the third antennal segment short, about $1 / 2$ length of the second one (Neotropical)................Lachnomyrmex Wheeler, 1910

7 Ventral surfaces of petiole and postpetiole with spongiform appendages (Borneo). Tetheamyrma Bolton, 1991

- Ventral surfaces of petiole and postpetiole without spongiform appendages.

8 Metanotal groove absent. Counting from the apex, the third antennal segment long, about as long as the second one (India)

Indomyrma Brown, 1986

- Metanotal groove present. Counting from the apex, the third antennal segment short, distinctly shorter than the second one.

9 Anterior margin of clypeus nearly straight in the middle portion. Metanotal groove widely deeply impressed. Propodeum with a pair of long slender spines. Propodeal spiracle large. Petiolar peduncle longer than the node (Oriental) (Figs. 1-7) Gaoligongidris gen. nov.

- Anterior margin of clypeus bluntly angled. Metanotal groove narrowly 
notched. Propodeum with a pair of short triangular teeth. Propodeal spiracle small. Petiolar peduncle not longer than the node (Indo-Australian) (Figs. 8-12) Lasiomyrma Terayama \& Yamane, 2000 10 Petiole sessile (Old World Tropics and Subtropics except Africa). Vollenhovia Mayr, 1865

- Petiole pedunculate 11

11 Anterior margin of clypeus with a pair of fork-like teeth in the middle (Old World Tropics) Calyptomyrmex Emery, 1887

- Anterior margin of clypeus without a pair of fork-like teeth in the middle

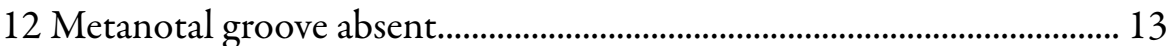

- Metanotal groove present ...................................................................... 14

13 Posterior clypeal extension narrower than frontal lobes. Propodeal spiracle large, its diameter greater than or about as long as the distance from spiracle to the declivity margin (U.S.A., Neotropical, Indo-Australian)

Rogeria Emery, 1894

- Posterior clypeal extension broader than frontal lobes. Propodeal spiracle small, its diameter about $1 / 3$ of the distance from spiracle to the declivity margin (Australia) Austromorium Shattuck, 2009

14 Propodeal spines anterolaterally curved and hook-like. Petiole with a pair of posteriorly curved spines (New Guinea)...... Ancyridris Wheeler, 1935

- Propodeal spines straight and not hook-like. Petiole without spines ... 15

15 Dorsum of alitrunk without any standing hairs ...................................... 16

- Dorsum of alitrunk with sparse to abundant standing hairs................... 17 16 Frontal carinae present. In profile view, dorsum of alitrunk with 5 hornlike processes (Indo-Australian) Proatta Forel, 1912

- Frontal carinae absent. In profile view, dorsum of alitrunk with 3 bluntly convex tubercles (Oriental) Dacatria Rigato, 1994

17 Clypeus without a pair of longitudinal carinae. Propodeal lobes strongly developed, elongate and broad (Borneo)

Propodilobus Branstetter, 2009

- Clypeus with a pair of longitudinal carinae. Propodeal lobes weakly developed, either short or narrow

18 Frontal carinae absent (Neotropical, Holarctic, Oriental, Indo-Australian) Stenamma Westwood, 1839 
- Frontal carinae present.

19 Petiolar peduncle longer than the node (Venezuela)

Bariamyrma Lattke, 1990

- Petiolar peduncle as long as or shorter than the node (Oriental, IndoAustralian, Australasian) .....................................Lordomyrma Emery, 1914

DESCRIPTIONS OF NEW GENUS AND SPECIES

\section{Gaoligongidris gen. nov.}

(Figs. 1-7)

Type-species: G. planodorsa sp. nov.

Gender: Feminine.

Etymology: The new genus is named after the type locality "Gaoligong" plus the common suffix "-idris".

Diagnosis of worker: Monomorphic terrestrial myrmicine ants with the following combination of characters.

Head square, occipital margin nearly straight.

Palp formula 2, 2 (2 individuals dissected).

Mandible triangular, with 6 sharp teeth which decrease in size from apex to base.

Median portion of clypeus longitudinally bicarinate, the posterior portion broadly inserted between the frontal lobes. Anterior clypeal margin extruding, nearly straight in the middle portion.

Anterior clypeal margin with a row of long setae, but lacking an isolated median seta.

Frontal lobes as broad as the posterior portion of clypeus which is inserted between them.

Frontal carinae and antennal scrobes absent.

Antennae 11-segmented; scapes short, apices failed to reach occipital corners; antennal clubs 3-segmented, the third segment of the club counting from apex reduced in volume and much shorter than the second one.

Eyes moderately large, drawn out anteroventrally, located before the midpoints of lateral sides of the head.

Promesonotum forming a high plateau, without teeth or prominences.

Promesonotal suture absent, metanotal groove deeply impressed. 
Propodeum low, with a pair of long slender spines.

Propodeal spiracles large and circular, well before the declivity margin and high up on the sides.

Propodeal lobes small and bluntly angled at apex.

Metapleural gland bullae large and close to the propodeal spiracles.

Tibial spurs absent from middle and hind legs.

Petiole with long anterior peduncle, the spiracles located about at the midlength of the peduncle, subpetiolar process absent.

Postpetiolar dorsum roundly convex, subpostpetiolar process absent.

Cuticle thick, sculptures strongly developed on the head, alitrunk, petiole, and postpetiole.

Pilosity abundant.

Female and male: Unknown.

Comparison: The new genus is close to the Indo-Australian genus Lasiomyrma Terayama \& Yamane (Figs. 8-12) in the tribe Stenammini, but with anterior clypeal margin not angled, metanotal groove deeply impressed, propodeal spiracles large, propodeal spineslong and slender, petiolar peduncle longer than the node.

Systematic position: Myrmicinae: Stenammini.

Geographical range: Oriental.

Discussion: At first glance, the new genus is somewhat similar to Lophomyrmex Emery of the tribe Pheidolini by the following characters: 11-segmented antennae, long propodeal spines, large propodeal spiracles, and long petiolar peduncle. However, the genus obviouslybelongs to the tribe Stenammini by the following characters: median portion of clypeus longitudinally bicarinate, anterior clypeal margin nearly straight in the middle portion; masticatory margins of mandibles with only 6 teeth; antennae short, apices of the scapes failed to reach occipital corners, the third segment of antennal club counting from apex distinctly reduced in volume and much shorter than the second one; pronotum without teeth, prominences, or lateral margins; head and alitrunk strongly sculptured.

\section{Gaoligongidris planodorsa sp. nov.}

(Figs. 1-7) 

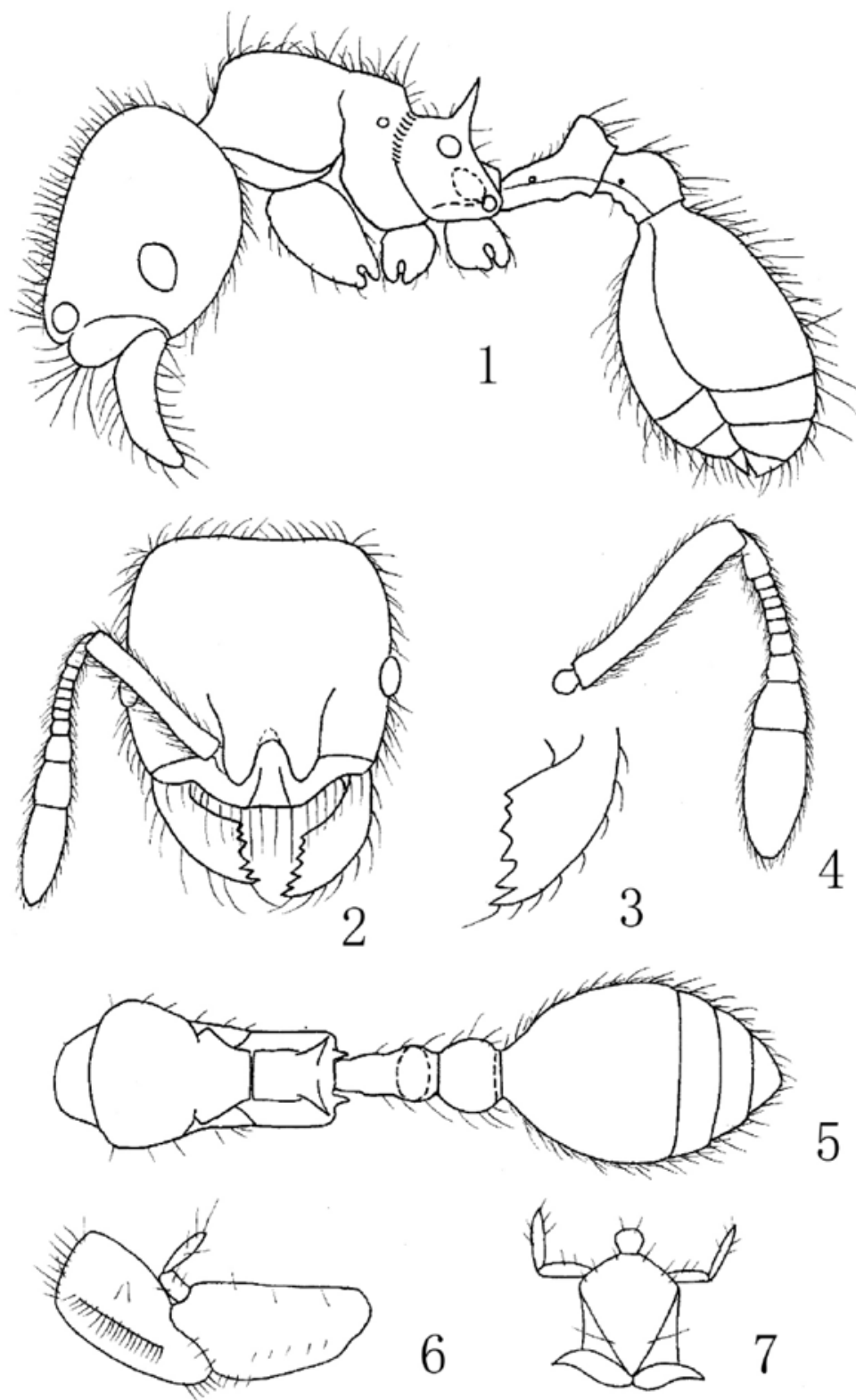

6

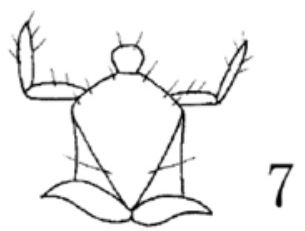

Figs. 1-7: Worker of Gaoligongidris planodorsa sp. nov.; 1. Head and body in profile view; 2. Head in full face view; 3. Mandible in dorsal view; 4. Antenna in dorsal view; 5. Body in dorsal view; 6. Maxilla and maxillary palp in ventral view; 7. Labium and labial palp in ventral view. 

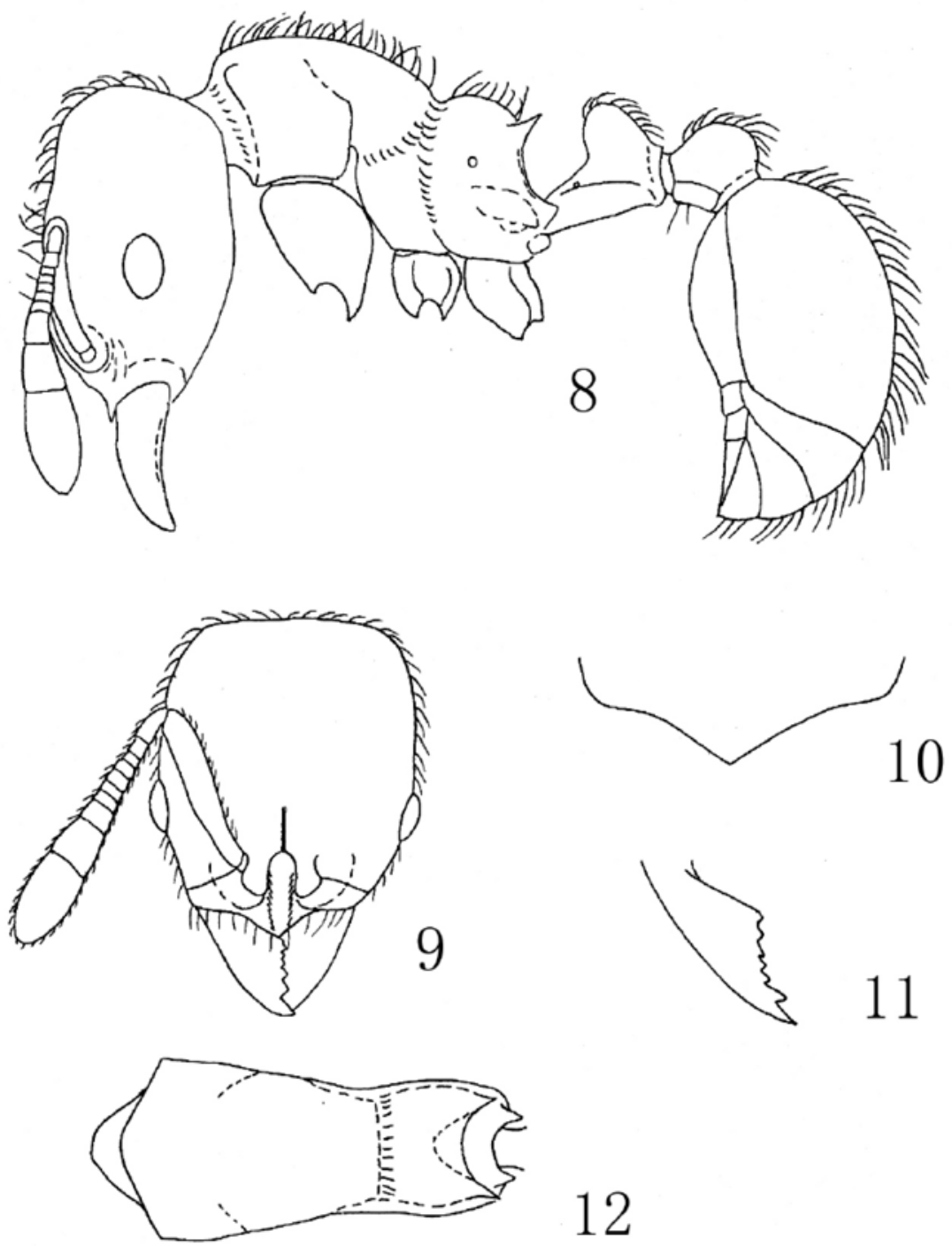

Figs. 8-12:Worker of Lasiomyrma gedensis Terayama \& Yamane; 8. Head and body in profile view; 9. Head in full face view; 10. Anterior clypeal margin in dorsal view; 11. Mandible in dorsal view; 12. Alitrunk in dorsal view. (Cited from Terayama \& Yamane 2000). 
Holotype worker: TL 2.6, HL 0.67, HW 0.65, CI 98, SL 0.43, SI 67, ED 0.10 , PW 0.42, AL 0.73.

Head square, as broad as long. Occipital margin nearly straight, occipital corners roundly prominent. Lateral sides weakly convex. Mandibles subtriangular, masticatory margin with 6 teeth, which decrease in size from apex to base. Median portion of clypeus bicarinate and extruding forward, anterior margin nearly straight. Posterior clypeal extension about as broad as the frontal lobes. Frontal carinae and antennal scrobes absent. Antennae short, 11-segmented, apex of scape reached to $3 / 4$ of the distance from antennal socket to occipital corner. The apical 3 segments form the antennal club, apical segment 2.5 times as long as the preceding one; the third segment counting from apex weakly enlarged, about $1 / 2$ length of the second one. Eyes moderately large, situated in front of the midpoints of the lateral sides of the head, with about 12 ommatidia in the maximum diameter.

In profile view, pronotum and mesonotum form a high plateau which gently slopes down backward, posterodorsal corner of mesonotum bluntly angled and steeply slopes down to the metanotal groove. Promesonotal suture absent. Metanotal groove deeply impressed. Propodeum low, dorsum short and straight. Propodeal spines long, sharp, and straight, laterally compressed, about as long as propodeal dorsum. Declivity weakly concave, lateral sides marginate. Propodeal spiracles large and circular, well before the declivity margins, and high up on the sides. Propodeal lobes small and bluntly angled at apex. Metapleural gland bullae large and roughly triangular. Petiolar node triangular, anterior face straight, posterior face weakly convex, anterior peduncle longer than the node, ventral face weakly concave under the node, and weakly convex before the concavity, subpetiolar process absent. Postpetiolar dorsum roundly convex, slightly lower than petiolar node, ventral face with 2 small convexities. In dorsal view, promesonotum nearly triangular, narrowed backward. Lateral sides of mesonotum marginate, lateroposterior corners rightly angled. Postpetiolar node about 1.4 times as broad as petiolar node, lateral sides of postpetiole roundly convex.

Mandibles densely longitudinally striate. Head densely reticulate, but the vertex longitudinally striate, interfaces finely punctured. Alitrunk densely coarsely punctured, but pronotal dorsum densely reticulate. Petiole and postpetiole densely finely punctured, but dorsum of postpetiolar node finely 
longitudinally striate. Gaster smooth and shining, but the first tergite with short basal costulae, which distinctly shorter than the postpetiolar node. Dorsum of head with dense erect short hairs. Dorsum of alitrunk with sparse erect to suberect longer hairs and abundant decumbent pubescence. Petiole, postpetiole, and gaster with abundant suberect hairs and decumbent pubescence. Scapes and tibiae with dense subdecumbent to decumbent short hairs. Color yellowish brown, but dorsum of head and middle portion of gaster blackish brown.

Paratype workers: TL 2.3-2.6, HL 0.60-0.67, HW 0.57-0.65, CI 89-100, SL 0.37-0.43, SI 63-67, ED 0.10-0.12, PW 0.37-0.42, AL 0.70-0.80 (10 individuals measured). As holotype, but color brownish yellow to yellowish brown.

Holotype: worker, CHINA: Yunnan Province, Tengchong County, Jietou Town, Datang Village, $2000 \mathrm{~m}$, collected from a soil sample in the subalpine moist evergreen broadleaf forest on the west slope of Gaoligong Mountain, 1999.V.1, Ji-Guai Li leg., No.A99-195.

Paratypes: 20 workers, with the same data as holotype; 3 workers, CHINA: Yunnan Province, Tengchong County, Jietou Town, Datang Village, $1750 \mathrm{~m}$, collected from a soil sample in the monsoon evergreen broadleaf forest, 1999.V.2, Qi-Zhen Long leg., No.A99-215; 3 workers, CHINA: Yunnan Province, Tengchong County, Shangying Town, Cuanlong Village, $1500 \mathrm{~m}$, collected from a soil sample in the monsoon evergreen broadleaf forest, 1999.IV.29, Qi-Zhen Long leg., No.A99-176; 6 workers, CHINA: Yunnan Province, Tengchong County, Jietou Town, Shaba Village, 2000m, collected from a ground sample in the shrub, 1999.V.3, Qi-Zhen Long leg., No.A99-320; 3 workers, with the same data as No.A99-320, but No.A99326, and collected from a soil sample; 1 worker, CHINA: Yunnan Province, Tengchong County, Qushi Town, Youtu Village, 2000m, collected from a ground sample in the subalpine moist evergreen broadleaf forest, 1999.V.4, Ji-Guai Li leg., No.A99-367; 2 workers, with the same data as No.A99-367, but Nos.A99-369, A99-376, and collected from soil samples; 2 workers, CHINA: Yunnan Province, Tengchong County, Qushi Town, Youtu Village, $1900 \mathrm{~m}$, collected from a ground sample in the subalpine moist evergreen broadleaf forest, 1999.V.4, Zheng-Hui Xu leg., No.A99-447; 1 worker, CHINA: Yunnan Province, Baoshan City, Bawan Town, Pumanshao Village, 2000m, 
collected from a ground sample in the subalpine moist evergreen broadleaf forest, 1998.VIII.13, Lei Fu leg., No.A98-2101; 1 worker, with the same data as No.A98-2101, but No.A98-2110 and collected from a soil sample.

Etymology: The name of the new species is descriptive of the "plane" promesonotal "dorsum" of alitrunk in profile view.

Remarks: Currently, G. planodorsa sp. nov. is the only species in the new genus. According to the rich collections, the new species is mainly found in subalpine moist evergreen broadleaf forest, sometimes habitats in the monsoon evergreen broadleaf forest and shrubs between the altitudes of $1500-2000 \mathrm{~m}$. The species is obviously nesting in the soil, and foraging on the ground.

\section{ACKNOWLEDGMENTS}

This study is supported by the Applied and Basic Research Foundation of Yunnan Province (No. 97C006G), the National Natural Science Foundation of China (No. 30870333), and the Key Subject of Forest Protection of Yunnan Province. I thank Miss Qi-Zhen Long, Mr. Ji-Guai Li, and Mr. Lei $\mathrm{Fu}$ (Students of Forest Protection Class 95-1, Southwest Forestry University, Kunming) for collecting the type specimens with me.

\section{REFERENCES}

Bolton, B. 1987. A review of the Solenopsis genus-group and revision of Afrotropical Monomorium Mayr. Bulletin of the British Museum (Natural History) (Entomology) 54: 263-452.

Bolton, B. 1991. New myrmicine ant genera from the Oriental region. Systematic Entomology 16: 1-13.

Bolton, B. 1994. Identification Guide to the Ant Genera of the World. Harvard University Press, 222 pp. Cambridge, Massachusetts.

Bolton, B. 1995. A New General Catalogue of the Ants of the World. Harvard University Press, 504 pp. Cambridge, Massachusetts.

Bolton, B. 2011. An Online Catalog of the Ants of the World. http://www.antcat.org/.

Branstetter, M.G. 2009. The ant genus Stenamma Westwood redefined, with a description of a new genus Propodilobus. Zootaxa 2221: 41-57.

Brown, W.L., Jr. 1986. Indomyrma dasypyx, new genus and species, a myrmicine ant from peninsular India. Israel Journal of Entomology 19 (1985): 37-49.

Brown, W.L.,Jr. \& E.O. Wilson 1957. Dacetinops, a new ant genus from New Guinea. Breviora 77: 1-7. 
Emery, C. 1887. Catalogo delle formiche esistenti nelle collezioni del Museo Civico di Genova. Parte terza. Formiche della regione Indo-Malese e dell'Australia (continuazione e fine). Annali del Museo Civico di Storia Naturale di Genova (2) 5 [25]: 427-473.

Emery, C. 1894. Studi sulle formiche della fauna Neotropica. Bullettino della Società Entomologica Italiana 26: 137-241.

Emery, C. 1908. Descriptions d'un genre nouveau et de plusiers formes nouvelles de fourmis du Congo. Annales de la Société Entomologique de Belgique 52: 184-189.

Emery, C. 1914. Les fourmis de la Nouvelle-Calédonie et des îles Loyalty. In Sarasin, F. \& Roux, J. Nova Caledonia Zoologie 1: 393-437. Wiesbaden.

Forel, A. 1912. Descriptions provisoires de genres, sous-genres et espèces de formicides des Indes orientales. Revue Suisse de Zoologie 20: 761-774.

Lattke,J.E. 1990. A new genus of myrmicine ants from Venezuela. Entomologica Scandinavica 21: 173-178.

Mayr, G. 1865. Reise der Österreichischen Fregatte Novara um die Erde in den Jahren 1857, 1858,1859 , unter den befehlen des Commodore B. von Wüllerstorf-Urbair.Zoologischer Theil. Formicidae: 119 pp. Wien.

Rigato, F. 1994. Dacatria templaris gen. n., sp. n. A new myrmicine ant from the Republic of Korea. Deutsche Entomologische Zeitschrift (N. F.) 1: 155-162.

Rosciszewski, K. 1994. Rostromyrmex, a new genus of myrmicine ants from Peninsular Malaysia. Entomologica Scandinavica 25: 159-168.

Shattuck, S.O. 2009. Austromorium, a new myrmicine ant genus from Australia. Zootaxa 2193: 62-68.

Terayama, M. \& S. Yamane 2000. Lasiomyrma, a new stenammine ant genus from Southeast Asia. Entomological Science 3: 523-527.

Weber, N.A. 1952. Studies on African Myrmicinae, 1. American Museum Novitates 1548: $1-32$.

Westwood, J.O. 1839. An Introduction to the Modern Classification of Insects; founded on the natural habits and corresponding organisation of the different families 2 (part 11): 193-224. London.

Wheeler, W.M. 1935. Two new genera of myrmicine ants from Papua and the Philippines. Proceedings of the New England Zoological Club 15: 1-9.

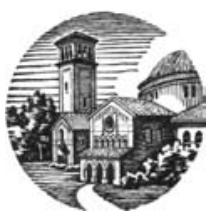

